\title{
МЕТОДИЧЕСКИЙ ПОДХОД К КУРСУ «ФИЗИКА ЧЕРЕЗ ПРИЗМУ НЕСТАНДАРТНЫХ ЗАДАЧ»
}

\section{METHODICAL APPROACH TO THE COURSE "PHYSICS THROUGH THE PRISM OF NON-STANDARD PROBLEMS"}

\section{E. Nelyubina \\ E. Bobkova \\ I. Grigoryants \\ K. Bogonosov}

Summary: A special place from the point of view of inclusion in the educational process today is occupied by elective courses, in particular in physics. They belong to extracurricular activities and are organized, as a rule, at the senior levels. However, the quality of the developed programs and teaching aids sometimes leaves much to be desired, so the analysis of the programs will be relevant and expedient.

In our work, we want to pay attention to the consideration of elective courses aimed at studying such a section of physics as "Physics through the prism of non-standard problems", this is due to the fact that this topic is key in the study of the school subject of physics and one of the main in preparing students for passing the final tests.

The problem is that today there are a number of shortcomings in the developed teaching aids for elective courses, therefore there is an acute problem in the development of educational and methodological complexes of elective courses that meet modern requirements.

\section{Purpose}

The purpose of the study is to design a program and educational and methodological support for the course "Physics through the prism of nonstandard problems" for 10th grade students who have chosen the physics and mathematics profile of education.

Results: the research is determined by the fact that a program has been developed and an educational and methodological complex has been designed for the elective course "Physics through the prism of non-standard tasks", which meet modern requirements for regulatory documents used in the organization of the educational process.

These developed documents have been partially tested and can be implemented in all educational institutions.

Keywords: teaching methods of physics, teaching, extracurricular activities, elective course, lesson.
Нелюбина Елена Георгиевна

К.п.н., дочент, ФГБОУ ВО «Самарский государственный социально-педагогический университет", г. Самара

nelubina.elena@pgsga.ru

Бобковаа Елена Юрьевна

К.п.н., дочент, Самарский филиал Московского городского педагогического университета, Самара vica3@yandex.ru

Григорьяни Игорь Александрович К.э.н., доцент, Самарский национальный исследовательский университет имени академика С.П. Королева

krater-i@list.ru

Богоносов Константин Александрович

К.т.н., доцент, Московский государственный университет технологий и управления им. К.Г. Разумовского (ПКУ), г. Москва kbogonosov@gmail.com

Аннотация: Особое место, с точки зрения включения в образовательный процесс, на сегодняшний день занимают элективные курсы, в частности по физике. Они относятся к внеурочной деятельности и организуются, как правило, на старших ступенях. Однако качество разработанных программ и методических пособий иногда оставляет желать лучшего, что подчеркивает актуальность проведения их методического анализа. В статье рассматриваются элективные курсы, направленные на изучение такого раздела физики, как «Физика через призму нестандартных задач». Выбор тематики элективного курса обусловлен тем фактом, что данная тема является ключевой при изучении физики в рамках школьного курса, и, как следствие, одной из главных тем, при подготовке учащихся к сдаче итоговых испытаний.

Проблема - на сегодняшний день в разработанных учебно-методических пособиях по элективным курсам существует ряд недочетов, что актуализирует необходимость разработки учебно-методических комплексов элективных курсов, соответствующих современным требованиям.

Цель исследования - спроектировать программу и учебно-методическое сопровождение курса «Физика через призму не стандартных задач» для учащихся 10-х классов, выбравших физико-математический профиль обучения. Результаты: результативность исследования определяется фактом разработки программы и успешным проектированием учебно-методического комплекса по элективному курсу «Физика через призму не стандартных задач», которые соответствуют современным требованиям, предъявляемым к нормативно-правовым документам, используемым в организации образовательного процесса.

Разработанные документы частично апробированы и могут быть реализованы во всех образовательных учреждениях.

Ключевые слова: методика преподавания физики, обучение, внеурочная деятельность, элективный курс, занятие.

следований является формирование образовательных продуктов, направленных на увеличение качественных критериев подготовки и удовлетворение потребностей обучающихся. Все образовательные продукты, предо- 
ставляемые учащимся, должны быть нацелены на развитие их способностей, умений и приспособительных свойств к адаптации в социально-экономических и технологических условиях развития современного социума. $[1,2,3]$

Ориентиром для трансформации является естественнонаучная область предметов, которая должна быть адаптирована под учет личностных особенностей обучающихся и направлена на их профессиональную ориентацию в системе современных технологических условий.

Отсюда возникает необходимость осуществления более широкого подхода при изучении предметов предметной области «Естественные науки» и возможность его осуществления через элективные курсы. [4]

Элективные курсы позволяют проектировать содержание естественнонаучной области образования при интенсификации процессов индивидуализированного подхода, учета личностных качеств обучаемого и предоставления информации о наиболее перспективных и актуальных направлений деятельности при выборе будущей профессии.

Одним из таких модулей может быть элективный курс «Физика через призму не стандартных задач». Данный проектируемый курс направлен на усиление научности при изучении разделов «Механика» и «Молекулярная физика», а так же позволяет осуществлять индивидуализированный подход в обучении, основанный на определенном типе мышления ученика, методы и технологии используемые при его реализации позволят увеличить качественные и количественные характеристики обучаемости, повысить уровень естественнонаучного мышления, развить механизм метапредметности в рамках изучаемых тем, дать информацию о дальнейших направлениях самореализации и самовыбора профессии.

В методико-психолого-педагогической отраслях наук накоплен опыт по построению различных элективных курсов по физике. Однако естественнонаучное образование в условиях современного обучения на сегодняшний день не обладает таким дидактическим и методическим инструментарием, практическая реализация которого на уровне физических знаний, в частности применительно к разделам «Механика» и «Молекулярная физика», могла бы способствовать естественнонаучной подготовке учащихся, соответствующей требованиям общества, потребностям и интересам учащихся. [5,6]

Приведенные данные в литературных источниках по проблемам современного состояния профильного естественнонаучного образования, демонстрируют необходимость в модернизации методологических, психолого-педагогических аспектов составления элективных курсов, а проанализированные исследования ряда авторов позволили вычленить некоторые противоречия с точки зрения регламентации образовательного процесса:

- между выдвигаемыми нормативами от государственных органов власти и реальными потребностями общества в гражданах, завершающих свое обучение в школе, которые должны обладать целостным мировоззрением, естественнонаучным мышлением, и объективным состоянием уровня подготовки выпускников, обладающих ограниченными навыками, находящимися на стадии формирования начальных представлений о развитии естественнонаучного мировоззрения;

- между быстрыми, постоянно изменяющимися темпами развития физических знаний в современной науке и недостаточной разработанностью дидактических механизмов их отражения в содержании физического образования, в частности при изучении разделов «Механика» и «Молекулярная физика» в классах естественнонаучного и физикоматематического профилей;

- между потенциальными возможностями более широкого изучения особо важных тем физики, обеспечивающих повышение качества естественнонаучной и физико-математической подготовки, развития естественнонаучного мышления учащихся и неудовлетворительным состоянием существующего учебно-методического обеспечения для классов естественнонаучного профиля и физико-математического профиля которое не позволяет реализовать данные возможности.

Все вышеизложенное актуализирует встает необходимость внедрения элективных курсов, направленных на углубленное изучение отдельных тем школьной программы, в систему работы школы на старших ступенях обучения.

В рамках исследования авторами 22 декабря 2020 года в рамках научно-методического семинара «Диссеминация передового педагогического опыта деятельности учителей Самарской области - 2020», проводимого на базе Самарского государственного социально-педагогического университета, было опрошено 33 учителя-предметника. Опрос проводился в форме анкетирования, направленного на выявление их отношения к элективным курсам. Базовым вопросом анкеты являлся следующий: Какую роль в учебном процессе вы отводите элективным курсам? По результатам анализа было установлено, что 85\% опрошенных (28 респондентов)), признают элективные курсы необходимыми для развития познавательного интереса учащихся и лишь 15\% (5 респондентов) считают, что элективные курсы являются лишней нагрузкой для учащихся. При этом, 100 \% из числа педагогов, ответивших утвердительно на вопрос о необходи- 
мости элективных курсов для развития познавательного интереса учащихся, отметили, что считают необходимым проводить элективный курс по физике.

Таким образом, анкетирование показало, что большинство педагогов признают необходимость элективных курсов в школе и считают, что они способствуют систематизации знаний учащихся, а также являются эффективными при подготовке к ЕГЭ, олимпиадам и творческим конкурсам.

На современном рынке образовательных услуг представлено достаточно большое количество уже разработанных элективных курсов, но самый главный недостаток в них, заключается в том, что, как правило, они не содержат полного учебно-методического сопровождения. [7]

В ходе исследования были выявлены следующие типовые недостатки:

1. авторами не указаны нормативные документы, которые являются регламентом составления и реализации рабочих программ;

2. отсутствует содержание элективного курса;

3. отсутствует описание учебно-методического и материально-технического обеспечения;

4. отсутствует методическое сопровождение элективного курса.

Разработка нашего элективного курса по физике реализовывалась с учётом таких нюансов современной системы среднего образования как переход на федеральные государственные стандарты, направленность образовательного процесса на достижение обучающимися новых образовательных результатов. [3,5]

Разработанный элективный курс по физике взаимодействует с процессом обучения физики в средней школе. При этом система курса способна подстраиваться и развиваться в зависимости от социального заказа общества.

Еще одним немаловажным условием успешной реализации курса является наличие методических рекомендаций для педагогов; пособий для учащихся, содержащих инструкции к проведению опытов, необходимый теоретический материал, изложенный в доступной и занимательной форме, а также комплекс заданий, стимулирующих школьников к занятиям учебно-исследовательской деятельностью по физике.

Учитывая все вышеперечисленные условия, особенности и рекомендации к составлению программы элективного курса, нами было сконструировано содержание элективного курса «Физика через призму не стандартных задач».
Цель курса: систематизировать и углубить представления учащихся о законах и понятиях, изучаемых разделах «Механика» и «Молекулярная физика», для подготовки к сдаче итоговых экзаменов по физики.

Процесс решения задач служит одним из средств овладения системой научных знаний по тому или иному учебному предмету. Особенно велика его роль при обучении физике, где задачи выступают основным средством формирования основополагающих физических знаний и умений. В процессе решения, обучающиеся овладевают методами исследования различных явлений природы, знакомятся с новыми прогрессивными идеями и взглядами, с открытиями отечественных ученых, с достижениями отечественной науки и техники, с новыми профессиями.

Программа элективного курса ориентирует на дальнейшее совершенствование уже усвоенных обучающимися знаний и умений. В программе выделены два основных раздела школьного курса физики, в начале изучения которых с обучающимися повторяются основные законы и формулы. При подборе задач по каждому разделу используются вычислительные, качественные, графические, экспериментальные задачи.

При решении задач особое внимание уделяется последовательности действий, анализу физического явления, проговариванию вслух решения, анализу полученного ответа.

При повторении обобщаются, систематизируются как теоретический материал, так и приемы решения задач, принимаются во внимание цели повторения при подготовке к единому государственному экзамену.

При изучении курса предусматривается самостоятельная работа в виде выполнения домашних заданий. Минимальный объем домашнего задания: 4-5 задач (1-2 задачи повышенного или высокого уровня с развернутым ответом, 2 - 3 задачи среднего уровня с кратким ответом).

Задачи курса:

- познакомить учащихся с классификацией задач по содержанию, целям, способам представления и содержанию информации

- совершенствовать умения решать задачи по алгоритму, аналогии, графически, геометрически и т.д.;

- использовать активные формы организации учебных занятий;

- развивать коммуникативные навыки, способствующие умению вести дискуссию, отстаивать свою точку зрения при обсуждении хода решения задачи;

- использовать нестандартные задачи для развития 
творческих способностей старшеклассников;

- развивать информационно-коммуникативные умения школьников при выполнении тестовых заданий с помощью компьютера.

Предусматриваются виды контроля, позволяющие оценивать динамику усвоения курса учащимися и получить данные для определения дальнейшего совершенствования содержания курса: кратковременные контрольные работы-тесты (по окончании каждого раздела)

В конце изучения курса проводятся итоговые занятия в форме мониторинговых работ, задания которых составлены на основе открытого банка заданий по физике http://www.fipi.ru/ и заданий сайта «Сдам ГИА: Решу ЕГЭ» https://phys-ege.sdamgia.ru/.

Мониторинговые работы рассчитаны на 2 часа и включают в себя до 15 заданий различного уровня сложности.

На изучение данного курса отводится 1 час в неделю в первом полугодии 10 класса. Программа курса рассчитана на 17 часов и предполагает ее изучение в течение первого полугодия учебного года: с учетом 1 часа в неделю.

\section{Содержание элективного курса:}

Введение (1 час)

Классификация задач. Алгоритмы решения каждого типа задач.

\section{Механика (9 час)}

Виды движения материальной точки. Графики зависимости физических величин от времени при различных видах движения материальной точки. Законы Ньютона. Движение тел по наклонной плоскости. Движение свя- занных тел. Периодическое движение. Графики зависимости величин от времени для вращательного и колебательного движения. Закон сохранения импульса. Абсолютно упругое и абсолютно неупругое соударение. Закон сохранения механической энергии.

\section{Термодинамика (5 час)}

Основное уравнение МКТ. Уравнение состояния идеального газа. Графическая интерпретация изопроцессов. Адиабатный процесс. Циклические процессы. Количество теплоты. Тепловой баланс. Графическое определение работы идеального газа.

Итоговый мониторинг (2 час). [10,11,12,13.14]

Курс включает материалы по физике, которые помогут расширить и углубить знания обучающихся о механике и молекулярной физике.

После изучения данного элективного курса учащиеся должны знать:

- Классификации задач;

- Методы решения задач;

- Основные правила и законы разделов «Механика» и «Молекулярная физика» с целью применения их к решению задач;

- Устройства и принципы действия измерительных приборов;

- Правила работы с приборами.

После изучения данного элективного курса учащиеся должны уметь:

- Анализировать физическое явление;

- Проговаривать вслух решение;

- Классифицировать предложенную задачу;

- Последовательно выполнять и проговаривать этапы решения задачи;

- Решать задачи повышенного и высокого уровня сложности;

Таблица 1.

Тематическое планирование курса

\begin{tabular}{|c|c|c|c|}
\hline № & Наименование темы & Кол-во часов & $\begin{array}{c}\text { Перечень обязательных л.р., п.р., к.р. и других } \\
\text { видов работ }\end{array}$ \\
\hline 1. & Введение & 1 & \multirow{10}{*}{$\begin{array}{l}\text { - Самостоятельная работа - } 2 \\
\text { - Кратковременная контрольная работа - } 4 \\
\text { - Тест - } 1 \\
\text { - Лабораторная работа - } 1\end{array}$} \\
\hline \multirow[t]{5}{*}{2.} & Механика & 9 & \\
\hline & 1.1. Кинематика материальной точки & 2 & \\
\hline & 1.2. Динамика материальной точки & 2 & \\
\hline & 1.3. Периодическое движение & 2 & \\
\hline & 1.4. Законы сохранения & 3 & \\
\hline \multirow[t]{3}{*}{3.} & Термодинамика & 5 & \\
\hline & 2.1 MKT & 2 & \\
\hline & 2.20 сновы термодинамики & 3 & \\
\hline 4. & Итоговый мониторинг & 2 & \\
\hline
\end{tabular}


- Решать комбинированные задачи;

- Владеть различными методами решения задачи: аналитическим, графическим, экспериментальными т.д.;

- Владеть методами самоконтроля и самооценки;

- Измерять физическую величину;

- Вычислять абсолютную и относительную погрешность прямых измерений;

- Самостоятельно анализировать полученные результаты и делать выводы.

В качестве ведущего подхода при разработке и реализации элективного курса по физике «Физика через призму не стандартных задач», нами был выбран личностно-ориентированный подход, поскольку личностную ориентацию обеспечивают те знания и умения, которые имеют непосредственную жизненную и практическую значимость. $[15,16,17]$

Учебно-методическое сопровождение включает в себя методические рекомендации для учителей и методические рекомендации для обучающихся, материал для проведения занятий.

Был подобран теоретический материал для проведения теоретических занятий, материал для проведения практических занятий, которые включают в себя как теоретический материал, так и задания на отработку полученных знаний, и материал для лабораторно-практических занятий, а также для итогового тестирования.

На сегодняшний день данный курс проходит апробацию в ряде школ Самарской области.

В заключении необходимо отметить, что в статье рассмотрена методическая система по реализации курса внеурочной деятельности «Физика через призму не стандартных задач», выполненное исследование вносит определенный вклад в развитие среднего общего образования. Вместе с тем, осознается факт того, что не все поставленные задачи решены в равной степени глубоко и основательно, а само исследование выявляет пласт проблем, изучение которых может и должно быть продолжено.

\section{ЛИТЕРАТУРА}

1. Федеральный государственный стандарт основного общего образования [Электронный ресурc]. URL: http://xn--80abucjiibhv9a.xn--p1ai/\%D0\%B4\%D0\%B E\%D0\%BA\%D1\%83\%D0\%BC\%D0\%B5\%D0\%BD\%D1\%82\%D1\%8B/543/(дата обращения: 25.09.20).

2. Федеральный государственный образовательный стандарт среднего общего образования [Электронный ресypc]. URL: http://xn--80abucjiibhv9a.xn--p1ai/ \%D0\%B4\%D0\%BE\%D0\%BA\%D1\%83\%D0\%BC\%D0 (дата обращения: 25.09.20).

3. Фундаментальное ядро содержания общего образования [Электронный ресурс]. URL: http://www.dagminobr.ru/storage/files/2015/f (дата обращения: 25.09.20).

4. Клячко, Т. Модернизация Российского образования: проблемы и решения [Текст]/ Т. Клячко // Отечественные записки. 2002. - №2. - С.48-55.

5. Алфёров Ю.С. Мониторинг развития образования в мире М.: Педагогика. - 2002. - №7.- С.88 - 95.

6. Аршанский, Е.А. Методические подходы к интеграции обучения [Текст]: для классов естественнонаучного профиля. Открытая школа. 2005. - №1. - С.61.

7. В.Е. Морозов. Физика. 10-11 классы[Текст]: сборник элективных курсов. Волгоград: Учитель, 2007 г.

8. Воронин Г.А. Элективные курсы: алгоритм создания, примеры программ[Текст]. Практическое руководство для учителя. М.: Айресс - Пресс, 2006. $118 \mathrm{c}$.

9. Каспржак А.Г., Иванова Л.Ф. Схема разработки программы авторского курса по выбору[Текст] // Модернизация. 2003. №1 С 10 - 13.

10. Лидин Р.А., Якимова Е.Е., Вотинова Н.А. Физика. 10-11 классы[Текст]: Учебное пособие. - М.: Дрофа, 2000

11. Протасов П.Н., Цитович И.К. Методика решения расчетных задач по физике. Пособие для учителя. [Текст] - М.: Просвещение, 1978.- 126с.

12. Гергей Т., Машбиц Е.И. Место задачи в деятельности. [Текст] — В сб.: Теория задач и способов их решения.— Киев, 1973. С. 3-13.

13. Машарова, Т.В. Основные положения личностно-ориентированной модели образования[Текст]/ Т.В. Машарова // Сознание-мировоззрение-мышление. Киров, 1998. - Вып. 3. - С. 137-148.

14. Климов, Г.А. Психология профессионального самоопределения. [Текст]/ Г.А. Климов. - Ростов-на-Дону: «Феникс», 1996. 512 с.

15. Эксперимент по совершенствованию структуры и содержанию общего образования [Текст]/ Под ред. А.В. Баранникова.- М.: АСТ Астрель, 2002. -221 с.

( ) Нелюбина Елена Георгиевна (nelubina.elena@pgsga.ru), Бобковаа Елена Юрьевна (vica3@yandex.ru), Григорьянц Игорь Александрович (krater-i@list.ru), Богоносов Константин Александрович (kbogonosov@gmail.com). Журнал «Современная наука: актуальные проблемы теории и практики» 